\title{
Insulin and Glucagon Secretion in BB Wistar Rats with Impaired Glucose Tolerance
}

\author{
A. F. Nakhooda, P. Poussier and E. B. Marliss \\ Department of Medicine, University of Toronto, Toronto, Ontario, Canada
}

Summary. Glucose tolerance and insulin secretion were studied in non-diabetic littermates $(n=154)$ of BB diabetic rats, aged 4-6 months. Initial screening involved two intraperitoneal glucose tolerance tests $(0.2 \mathrm{~g} / 100 \mathrm{~g}$ body weight) performed one week apart. Nineteen rats $(12 \%)$ were found to have impaired tolerance which persisted in 14 (74\%) (group 1) and was transient in five animals (group 2). Seven rats progressed to overt diabetes in group 1, but none in group 2. Group 1 was characterized by (a) sustained abnormalities in glucose response to oral and intraperitoneal glucose, as well as intraperitoneal tolbutamide and arginine; (b) fasting hypoinsulinaemia; (c) decreased insulin response to glucose and tolbutamide; (d) suppression of the early and late phases of immunoreactive insulin response to intravenous glucose; (e) no systematic abnormalities in glucagon secretion; and (f) the presence of significant insulitis. The group 2 rats had (a) normal glycaemic response to oral and intraperitoneal glucose, tolbutamide and arginine on further testing; (b) normal fasting insulin but excessive insulin response to glucose and tolbutamide, but not to arginine, and (c) mainly normal islet morphology. Thus, impaired glucose tolerance may occur in $\mathrm{BB}$ rats with either hypoinsulinaemia or hyperinsulinaemia.

Key words: Type I diabetes, BB rat, impaired glucose tolerance, animal model, insulin, glucagon, insulitis, glucose, arginine, tolbutamide.
The spontaneously diabetic BB Wistar rat displays a diabetic syndrome akin to that of human insulin-dependent diabetes [1-5]. Typically, an extensive insulitis causes almost total destruction of pancreatic B cells, resulting in insulin deficiency and its expected metabolic consequences. Genetic and immune factors have been implicated in the aetiology of the islet lesion [reviewed in 5]. Earlier stages and/or milder degrees of the same process are demonstrable in BB rats without total insulin lack [3-5]. Thus, rats with sustained impairment of intragastric or intraperitoneal glucose tolerance are found, as well as some with transient glycosuria. A period of impaired glucose tolerance (IGT) may precede insulin-dependent diabetes, and may be associated with increased, normal or decreased insulin responses to glucose stimulation $[2,4,5]$. The frequency of IGT appears to vary from 10 to $25 \%$ in individual litters.

The present study was designed to evaluate the time course of IGT, to define whether this state may be transient, sustained indefinitely, or a stage in the development of overt diabetes. To determine the nature of possible defects in control of insulin and glucagon release, we used repeated intragastric and intraperitoneal glucose, and intraperitoneal arginine and tolbutamide challenges. Furthermore, to detail whether the defects found were specific to early versus later phases of secretion, we used a pancreas preparation in situ employing portal vein catheterization.

\section{Materials and Methods}

One hundred and fifty-four BB rats from 35 litters (114 males and 40 females), aged 4-6 months, were obtained from Dr. A. A. Like (Department of Pathology, University of Massachusetts, Worcester, Massachusetts, USA) and from Dr. P. Thibert (Animal Resources Division, Health Protection Branch, Ottawa, Ontario, Canada). These rats were the 'non-diabetic' members of litters which had produced overtly diabetic rats (average incidence $22 \pm 6 \%$ ). The rats were housed under light and climate-controlled conditions and fed powdered Purina lab chow (Ralston-Purina, Woodstock, Ontario, Canada) and water ad libitum.

All rats were screened initially using two IP glucose tolerance tests $(0.2 \mathrm{~g} / 100 \mathrm{~g}$ body weight) performed one week apart in the morning and following an $18-20 \mathrm{~h}$ fast. Blood samples were obtained from the tail vein without anaesthesia before and $1 \mathrm{~h}$ after glucose injection. More detailed studies were then performed on rats that showed two consecutive abnormal IP glucose tolerance tests (1-h glucose value $>14 \mathrm{mmol} / \mathrm{l})$. These animals were further challenged with glucose administered either by gavage (oral glucose tolerance test, $0.25 \mathrm{~g}$ / $100 \mathrm{~g}$ body weight $)$ or IP $(0.2 \mathrm{~g} / 100 \mathrm{~g}$ body weight); with IP sodium tolbutamide $(10 \mathrm{mg} / 100 \mathrm{~g}$ body weight); and with IP arginine monohydrochloride $(210 \mathrm{mg} / 100 \mathrm{~g}$ body weight, $\mathrm{pH} 7.4)$. The glucose and arginine challenges were performed on the morning after an overnight fast $(18-20 \mathrm{~h})$ and the tolbutamide test after a 6 -h fast from $09.00-15.00 \mathrm{~h}$.

Blood was sampled from the orbital sinus under light ether anaesthesia and the plasma assayed for glucose, immunoreactive insulin (IRI) and immunoreactive glucagon. A 7-10 day recovery interval was introduced between tests. Littermates of the rats found to display IGT, that had shown two normal consecutive IP glucose tolerance tests during the screening tests were used as controls. Finally, 12 rats (six with IGT, six controls) were studied further for islet hormone secretion with an in vivo method which we have designated the 'in situ 


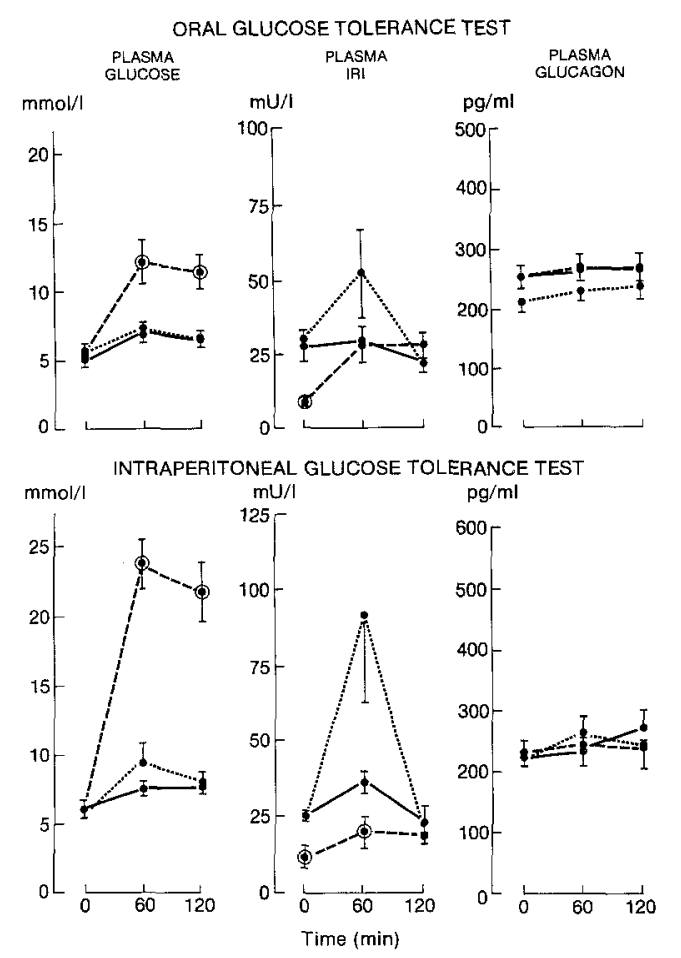

Fig. 1. Mean plasma glucose, insulin (IRI) and glucagon responses (upper panel) during oral glucose tolerance tests $(0.25 \mathrm{~g} / 100 \mathrm{~g}$ body weight) and (lower panel) IP glucose tolerance tests $(0.2 \mathrm{~g} / 100 \mathrm{~g}$ body weight), in control ( $-n=16)$, group $1(-\ldots, n=13)$ and group $2(\cdots \bullet, n=5)$ rats with impaired glucose tolerance. Large circles denote the values in groups 1 and 2 that are significantly different from the corresponding values in the control group $(p<$ 0.05 ). Values are shown as mean \pm SEM

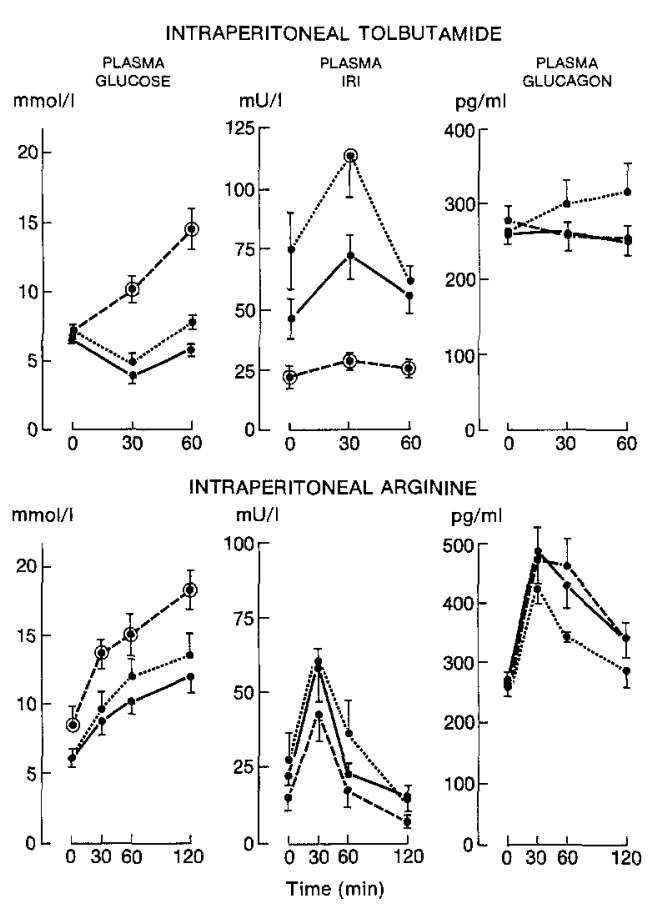

Fig. 2. Mean plasma glucose, insulin (IRI) and glucagon responses (upper panel) to IP sodium tolbutamide $(10 \mathrm{mg} / 100 \mathrm{~g}$ body weight), and (lower panel) to arginine hydrochloride $(210 \mathrm{mg} / 100 \mathrm{~g}$ body weight) in control $(\bullet, n=14)$ and group $1(\bullet-\cdots, n=12)$ and group $2(\cdots \bullet, n=5)$ rats with impaired glucose tolerance. Data are presented as in Figure 1 pancreas preparation'. This method has been employed previously [6]. Briefly, under pentothal anaesthesia, catheters were introduced into the jugular vein and portal vein. The latter followed removal of all the small and large intestine from the level of the ligament of Treitz to the rectum. This allowed for collection of portal blood draining only stomach, spleen, proximal small intestine, and pancreas. The abdomen was closed, body temperature maintained constant at $37^{\circ} \mathrm{C}$ by a warming device, and the rat allowed to breathe oxygen-enriched air spontaneously. Arterial $\mathrm{pH}$ and $\mathrm{PaCO}_{2}$ were shown to be adequately maintained in this manner. Blood volume was replaced quantitatively after each sampling using blood from a normal rat donor. Catheter placement was verified at the end of each experiment. After a control period of $20 \mathrm{~min}$ for stabilization following the surgical preparation, an IV glucose bolus ( $1 \mathrm{~g} / \mathrm{kg}$ body weight) was administered into the jugular vein followed by frequent blood sampling for a period of $60 \mathrm{~min}$. A priming bolus of arginine-hydrochloride $(312.5 \mu \mathrm{mol})$ was then administered followed by a constant infusion of $62.5 \mu \mathrm{mol} / \mathrm{min}$ over $15 \mathrm{~min}$, with blood sampling for a further period of $60 \mathrm{~min}$.

At sacrifice, the pancreas of each animal was removed immediately and fixed in Bouin's solution. For light microscopic examination, paraffin-embedded sections were stained with haematoxylin and eosin and with glutaraldehyde/fuchsin.

Plasma glucose was estimated using the glucose oxidase method of the Beckman Glucose Analyzer II (Model 6517, Beckman Instruments, Fullerton, California, USA). IRI was estimated by a singleantibody, charcoal-separation method, using rat insulin standard [1, 2]. This assay is sensitive to a lower level of $2.5 \mathrm{mU} / 1$, and has a coefficient of variation of $5 \%$. Immunoreactive glucagon was estimated in plasma containing aprotinin (Trasylol, Miles Pharmaceuticals, Rexdale, Ontario, Canada) using Unger $30 \mathrm{~K}$ antiserum $[1,2]$. Infused glucose was a commercial $50 \%$ dextrose in water preparation whose concentration was verified. Arginine hydrochloride was obtained from Sigma Chemicals, St. Louis, Missouri, USA, and sodium tolbutamide solution from Hoechst Pharmaceuticals, Montreal, Quebec, Canada. SEM.

Unless otherwise indicated all values are expressed as mean \pm

\section{Results}

\section{Frequency of Impaired Glucose Tolerance}

Of the 154 rats studied, 19 rats $(12 \%)$ were considered to have IGT with normal fasting glucose values $(5.17 \pm$ $0.11 \mathrm{mmol} / \mathrm{l})$ but abnormal post-challenge values of $20.7 \pm 1.0$ and $17.9 \pm 1.3 \mathrm{mmol} / 1$ during the two consecutive screening IP glucose tolerance tests (normal: $10.4 \pm 1.1 \mathrm{mmol} / \mathrm{l}$ ). These post-challenge values were greater than two standard deviations above the mean normal values. With further testing, the IGT rats fell into two groups. In rats designated group 1 ( $n=14$, eight males and six females), the animals continued to exhibit hyperglycaemic responses to the subsequent challenge tests reported below. In those designated group $2(n=$ 5 , all males), the glucose responses reverted to normal. In group 1, seven of the 14 rats progressed to overt diabetes within 1-20 weeks after the commencement of the study. None of the group 2 animals or those designated as control littermates, became diabetic. Weights of all IGT animals were not distinguishable from those of littermate controls, except upon later occurrence of overt diabetes.

\section{Oral Glucose Tolerance Test (Fig I)}

In group 1, fasting plasma glucose was normal but rose to significantly higher than control levels at 60 and 

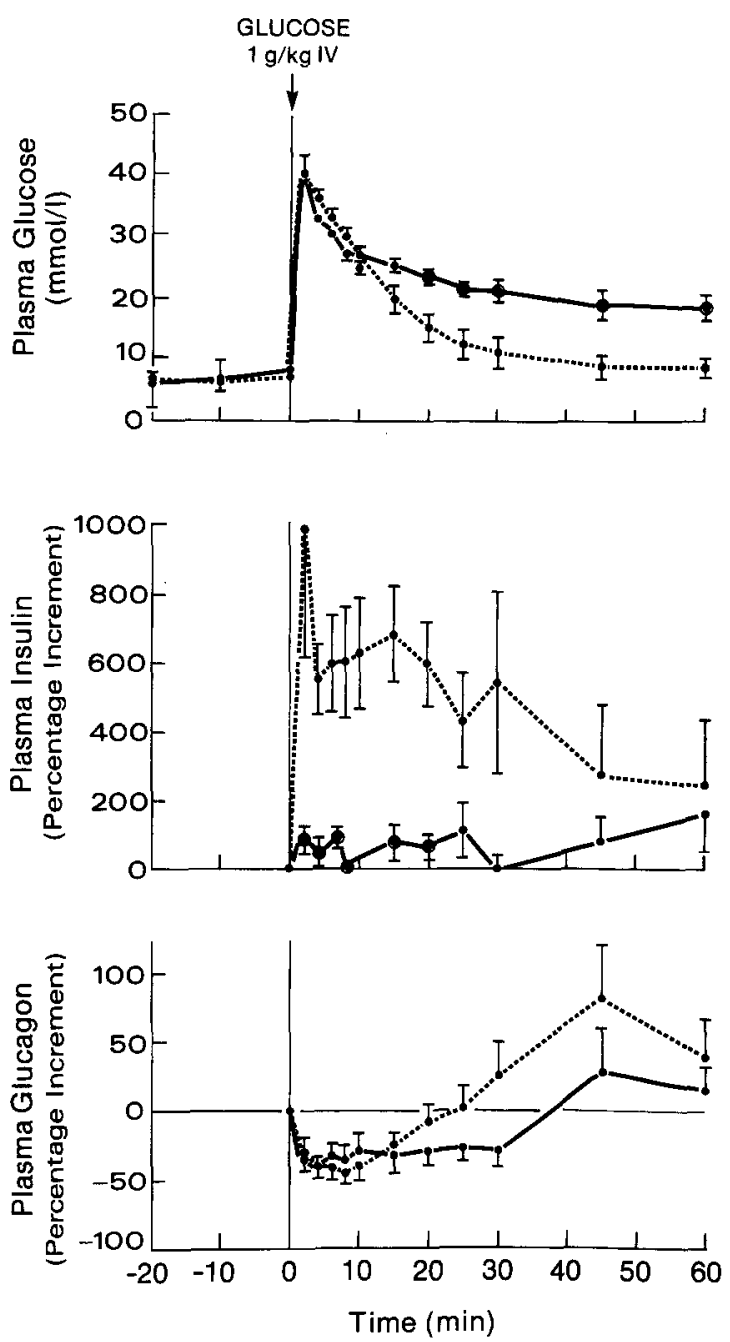

Fig.3. Portal vein plasma glucose, insulin and glucagon responses of control $(\bullet \ldots, n=6)$ and group 1 rats $(\longrightarrow, n=4)$ with impaired glucose tolerance to an IV bolus of glucose $(1 \mathrm{~g} / \mathrm{kg}$ body weight). Hormone responses are presented as a percentage increment above control values. Large circles denote values significantly different between control and group 1 rats $(p<0.05)$

$120 \mathrm{~min}(p<0.05)$. Unexpectedly, fasting plasma IRI was significantly lower $(p<0.05)$ but post-challenge values rose to within the normal range. In group 2, the glucose response was normal. Mean plasma IRI at 60 min was somewhat higher though not significantly so (with very high values in some individual rats) but within the normal range at 120 min. Fasting plasma glucagon was normal in both IGT groups, and glucose challenge caused no variation in any of the rats.

\section{Intraperitoneal Glucose Tolerance Test (Fig 1)}

In group 1, the post-glucose hyperglycaemia was considerably greater at both 60 and 120 min than with the oral challenge. Again plasma IRI was significantly lower than in control rats at time 0 , but in this case it remained lower at $60 \mathrm{~min}$. In group 2, although the glucose levels were not different from those of the control rats, the plasma IRI values at $60 \mathrm{~min}$ were threefold higher. Immunoreactive glucagon was again similar in all groups and showed no post-glucose response.

\section{Intraperitoneal Tolbutamide Test (Fig 2)}

The normal rats responded with a fall in glucose levels and a rise in IRI at $30 \mathrm{~min}$. Surprisingly in group 1, glycaemia increased progressively after tolbutamide administration to $10.3 \pm 0.9$ and $14.9 \pm 1.4 \mathrm{mmol} / 1$ at 30 and $60 \mathrm{~min}$, respectively. Plasma IRI, both fasting and post-challenge, was significantly lower than control levels. Immunoreactive glucagon showed no response in either normal or group 1 rats. In group 2, mean glycaemia decreased normally to $4.9 \mathrm{mmol} / \mathrm{l}$ at $30 \mathrm{~min}$, but as with the IP glucose tolerance tests plasma IRI levels were significantly higher than in control rats. Immunoreactive glucagon in group 2 showed a small but nonsignificant upward trend. The higher fasting IRI values observed for all the rats in this test is due to the length of the fasting period before sampling being only $6 \mathrm{~h}$.

\section{Intraperitoneal Arginine- $\mathrm{HCl}$ Test (Fig 2)}

The normal rats showed a progressive increase in glycaemia, and a transient IRI response at $30 \mathrm{~min}$. Both fasting and post-challenge glucose values in group 1 were significantly higher than in the control rats $(p<$ 0.001 ). In contrast to the previous challenges, plasma IRI responded in a similar manner to the controls. The greater glycaemic rise was associated with plasma glucagon increments which showed no differences between controls and group 1. In group 2, the responses of glucose, IRI and glucagon were similar to those of the controls.

\section{Dynamics of Insulin and Glucagon Secretion} (Figs 3 and 4)

Hormone responses are presented as percentage increment over control values because the 'in situ pancreas preparation' shows considerable inter-individual variation in absolute values both before and following challenges. After an IV glucose bolus (Fig 3), glucose disappearance was significantly reduced in the group 1 rats with mean $\mathrm{K}_{\mathrm{g}}$ of $2.12 \pm 0.74 \% /$ min compared with 5.30 $\pm 0.72 \% / \mathrm{min}$ in control rats $(p<0.05)$. From a mean pre-infusion IRI value of $137.2 \pm 58.2 \mathrm{mU} / \mathrm{ml}$, the control rats showed a typical biphasic response with a peak increment of $1000 \pm 370 \%$ during the early phase and $690 \pm 149 \%$ during the plateau of the late phase. In group 1 rats, the pre-glucose insulin value was $395 \pm$ $162 \mathrm{mU} / 1$ and a markedly attenuated response to glucose was found during both phases of secretion. The glucagon response was similar in both groups. From comparable mean pre-infusion values (controls: $1.47 \pm$ $0.19 \mathrm{ng} / \mathrm{ml}$, group 1: $2.84 \pm 1.04 \mathrm{ng} / \mathrm{ml}$ ), it decreased transiently during the first $20 \mathrm{~min}$ by $50 \%$ in both 

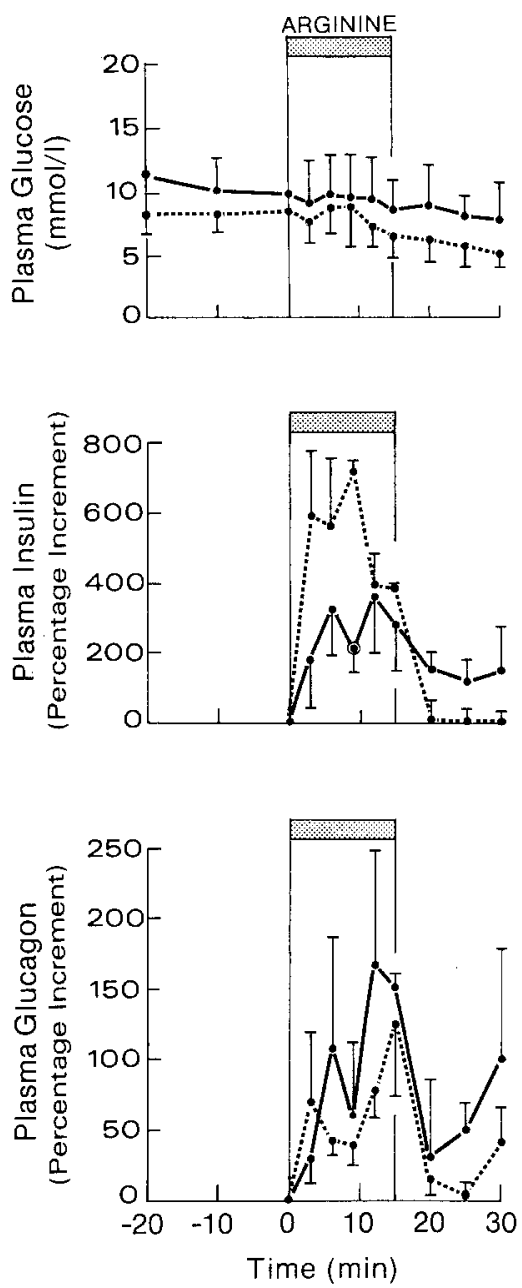

Fig.4. Portal vein plasma glucose, insulin and glucagon responses of control $(\bullet \cdots, n=6)$ and group 1 rats $(\longrightarrow, n=4)$ with impaired glucose tolerance to a 15 min primed IV infusion of arginine hydrochloride. Data are presented as in Figure 3

groups. In the control rats, a significant rebound above pre-glucose values was observed between 45 and $60 \mathrm{~min}$ $(p<0.05)$; this was not seen in the group 1 rats. Two rats from group 2 were studied in this manner. Although their $\mathrm{K}_{\mathrm{g}}$ values were abnormal $(2.66$ and $2.77 \% / \mathrm{min})$, the insulin response was excessive in one and within the normal range in the other (data not shown).

During arginine infusion (Fig 4), the glucose values did not change in either control or group 1 rats. In group 1, the pre-infusion values appeared somewhat higher, possibly reflecting the residual hyperglyceamia from the preceding IV glucose bolus given $60 \mathrm{~min}$ earlier. Insulin levels were comparable before the infusion (control: $132.8 \pm 49.2 \mathrm{mU} / 1$, group 1: $177.0 \pm$ $90.2 \mathrm{mU} / 1)$. Although the group 1 response appeared delayed and somewhat diminished, these differences were not significant. A distinct early phase response was not observed. Immunoreactive glucagon values showed a biphasic response, which was similar in both groups, though with a delayed early peak in group 1 . The mean pre-infusion values were $1.71 \pm 0.30$ and
$2.64 \pm 1.73 \mathrm{ng} / \mathrm{ml}$ for control and group 2 rats, respectively. In the two group 2 rats, the insulin response was analogous to that during the IV glucose tolerance test, being excessive in the same rat and normal in the other. Glucagon response was normal (data not shown).

\section{Pancreatic Morphology}

The pancreases of rats from group 1 were all abnormal. Of the 11 rats studied, four had developed insulin-dependent diabetes and showed only 'end stage' islets: small and few in number, most with no residual inflammatory cells, and with few or no cells staining with glutaraldehyde/fuchsin. All seven rats which remained glucose intolerant showed active insulitis, of variable intensity. In all pancreases positive glutaraldehyde/fuchsin-staining cells were found, but either with an apparent reduction in numbers in all islets, or with some islets completely spared and others completely negative. In group 2, of the three pancreases available for study, two were normal and the third showed a mixed picture with most islets normal but some displaying moderate mononuclear cell infiltration. Islets from 12 control rats were all normal.

\section{Discussion}

Based upon earlier characterizations of this diabetic syndrome $[1-3,7,8]$, the islet lesion presents with varying degrees of severity and differing time-courses $[4,5]$. An immunological disorder in genetically susceptible animals is associated with insulitis which may be overwhelming and destroy virtually all B cells, severe but transient, or with variable sparing of islets or regeneration of affected ones. All variants of the metabolic derangement and islet lesion have been described [1-5], but control of hormone secretion corresponding to each has not been hitherto detailed. In the overt diabetic state, essentially no insulin response to glucose, tolbutamide or arginine is found $[1,3]$.

The present study emphasizes (a) the frequency with which IGT may be found, (b) the need to test for it among littermates of rats with insulin-dependent diabetes in order to establish the true frequency of the phenotype(s), and (c) that many rats with IGT progress to insulin-dependent diabetes. These findings, in addition to our recent observations on the prevalence of lymphopenia in all clinical forms and its possible utility as a marker for susceptibility $[9,10]$, demonstrate that compelling genetic studies will require more than routine testing for glycosuria and hyperglycaemia. Such lymphopenia has been confirmed by others [11].

In addition, this study has demonstrated several features of hormone secretion in IGT. The group 1 IGT rats showed (a) sustained abnormality of glucose tolerance, IP and orally (b) paradoxical hyperglycaemic re- 
sponse to tolbutamide, (c) fasting hypoinsulinaemia and subnormal IRI response to glucose and tolbutamide, (d) exaggerated glycaemic response to IP arginine, with concurrent normal IRI response, (e) attenuation of both early and late phases of IRI response to intravenous glucose, (f) only slight decrease in IRI response to arginine, (g) no systematic abnormality in glucagon secretion, and (h) all showed significant insulitis.

Many of the foregoing results in group 1 could be explained by the islet lesion destroying a sufficient proportion of B cells to result in decreased total secretory capacity. The fasting euglycaemia in the face of decreased IRI implies increased insulin sensitivity [12]. An alternate hypothesis would be that the total secretory capacity is decreased by virtue of altered function of $B$ cells, but with a larger number of surviving cells. The only exception to the general insulin secretory failure appears to be in the responses to arginine. In both intraperitoneal and intravenous arginine studies, however, higher glycaemic values prevailed. Interaction of hyperglycaemia with arginine [13] or potentiation of the response to arginine by concurrent hyperglycaemia [14] cannot be excluded. Similar findings have been reported in perfused pancreases of rats given streptozotocin in the neonatal period then studied several weeks later [15].

In contrast to the IGT rats of group 1, those of group 2 showed (a) normal glycaemic responses to glucose, tolbutamide and arginine, and (b) normal fasting IRI, but excessive insulin responses to glucose and tolbutamide, but not to arginine. The islets in three pancreases showed no gross alterations, suggesting that altered pancreatic function in this group of rats may be due either to the presence of abnormal molecular forms of insulin and/or abnormal regulation of its secretion.

This study has identified types and/or stages of the syndrome other than overt diabetes. With the possibility of identification of susceptible rats by the presence of lymphopenia [9-11], and their testing for IGT, very precise evaluation of, and correlation between, structural and functional abnormalities is now possible. In the past, sequential testing of relatives of diabetic patients has not given conclusive evidence for insulin secretory or glucoregulatory abnormalities before the occurrence of diabetes [16, 17]. However, more recently, Hollander et al. have shown that HLA-identical siblings of children with Type 1 diabetes show both glucose intolerance and hyperinsulinaemia [18]. These findings give added relevance to the detailed pursuit of mechanisms of abnormalities seen in the BB rat.

Acknowledgements. The authors express their gratitude to Drs. P. Thibert and A.A. Like for supplying the BB rats used in this study, to Dr. A. A.F.Sima for the morphological observations, to A.N. Stein, C. N. Wei, M. Grose and H. Gupta for their assiduous technical assistance, and to S. Bailey for her excellent secretarial services. These studies were supported in part from grants from the Medical Research Council of Canada (MA-6540) and the National Institutes of Health (AM-25371).

\section{References}

1. Nakhooda AF, Like AA, Chappel CI, Murray FT, Marliss EB (1977) The spontaneously diabetic Wistar rat. Metabolic and morphologic studies. Diabetes 26: 100-112

2. Nakhooda AF, Like AA, Chappel CI, Wei C-N, Marliss EB (1978) The spontaneously diabetic Wistar rat (the 'BB' rat): Studies prior to and during development of the overt syndrome. Diabetologia 14: 199-207

3. Nakhooda AF, Wei C-N, Like AA, Marliss EB (1978) The spontaneously diabetic Wistar rat (the 'BB' rat). A study of rats with transient glycosuria. Diabete Metab 4: 255-259

4. Marliss EB, Sima AAF, Nakhooda AF (1981) Spontaneous diabetes in the 'BB' Wistar rat. In: Martin JM, Ehrlich R, Holland FJ (eds) Etiology and pathogenesis of insulin dependent diabetes mellitus. Raven Press, New York, pp 251-274

5. Marliss EB, Nakhooda AF, Poussier P, Sima AAF (1982) The diabetic syndrome of the 'BB' Wistar rat: Possible relevance to Type 1 (insulin-dependent) diabetes in man. Diabetologia 22: 225-232

6. Marre M, Bobbioni E, Suarez M, Reach G, Dubois MP, Assan R (1979) Control of gastric glucagon secretion in the acutely pancreatectomized rat. Diabetes 28: 213-220

7. Nakhooda AF, Wei C-N, Marliss EB (1980) Muscle protein catabolism in diabetes: 3-methylhistidine excretion in the spontaneously diabetic 'BB' rat. Metab Clin Exp 29: 1272-1277

8. Nakhooda AF, Sole MJ, Marliss EB (1981) Adrenergic regulation of glucagon and insulin secretion during immobilization stress in normal and spontaneously diabetic BB rats. Am J Physiol 240 (Endocrin Metab 3) E373-378

9. Poussier P, Nakhooda AF, Sima AAF, Marliss EB (1981) Lymphopenia in the spontaneously diabetic 'BB' Wistar rat. Diabetologia 21: 317 (Abstract)

10. Poussier P, Nakhooda AF, Falk JA, Marliss EB (1982) Lymphopenia and abnormal lymphocyte subsets in the 'BB' rat: Relationship to the diabetic syndrome. Endocrinology 110: 1825-1827

11. Jackson R, Rassi N, Crump T, Haynes B, Eisenbarth GS (1981) The diabetic rat: profound T-cell lymphocytopenia. Diabetes 30 : $887-889$

12. Kobayashi M, Olefsky JM (1979) Effects of streptozotocin induced diabetes on insulin binding, glucose transport and intracellular glucose metabolism in isolated rat adipocytes. Diabetes 28: $87-95$

13. Norfleet NT, Pagliara AS, Haymond MW, Matschinsky F (1975) Comparison of alpha and beta-cell secretory responses in islets isolated with collagenase and in the isolated perfused pancreas of rats. Diabetes 24: 961-970

14. Pfeifer MA, Halter JB, Porte D Jr (1981) Insulin secretion in diabetes mellitus. Am J Med 70: 579-588

15. Weir GC, Clore ET, Zmachinski CJ, Bonner-Weir S (1981) Islet secretion in a new experimental model for non-insulin-dependent diabetes. Diabetes 30: 590-595

16. Kahn CB, Soeldner JS, Gleason RE, Rojas L, Camerini-Davalos RA, Marble A (1963) Clinical and chemical diabetes in offspring of diabetic couples. N Engl J Med 281: 343-347

17. Tattersall RB, Fajans SS (1975) Prevalence of diabetes and glucose tolerance in 199 offspring of thirty-seven conjugal diabetic parents. Diabetes 24: 452-455

18. Hollander P, Asplin C, Hansen J, Palmer JP (1980) Beta cell dysfunction in HLA identical siblings of insulin-dependent diabetics. Diabetes 29 (Suppl 2): 54 A (Abstract)

Received: 19 October 1981

and in revised form: 23 August 1982

Dr. E. B. Marliss

McGill Nutrition and Food Science Centre

Royal Victoria Hospital

687 Pine Avenue West

Montreal, Quebec H3A 1A1

Canada 